\title{
High serum level of interleukin-6 is linked with dyslipidemia in oral lichen planus
}

\author{
MIHAELA PAULA TOADER ${ }^{1}$, TATIANA TARANU ${ }^{1}$, MARIA MAGDALENA CONSTANTIN ${ }^{2}$, \\ DOINITA OLINICI ${ }^{3}$, MADALINA MOCANU $^{1}$, VICTOR VLAD COSTAN ${ }^{4}$ and STEFAN TOADER $^{5}$ \\ ${ }^{1}$ Department of Oral Dermatology, 'Grigore T. Popa' University of Medicine and Pharmacy, 700115 Iasi; \\ ${ }^{2}$ Department of Dermatology, 'Carol Davila' University of Medicine and Pharmacy, 020125 Bucharest; \\ Departments of ${ }^{3}$ Morphofunctional Sciences 2, ${ }^{4}$ Oral and Maxillofacial Surgery and ${ }^{5}$ Pathophysiology, \\ 'Grigore T. Popa' University of Medicine and Pharmacy, 700115 Iasi, Romania
}

Received October 16, 2020; Accepted November 16, 2020

DOI: 10.3892/etm.2021.10419

\begin{abstract}
Oral lichen planus (OLP) is a complex chronic inflammatory disorder in which autocytotoxic $\mathrm{CD}^{+} \mathrm{T}$ cells, locally present in the affected tissue, induce basal keratinocyte apoptosis, through the release of several cytokines, such as interleukin-6 (IL-6). IL-6 is a proinflammatory cytokine that is related to alterations in lipid metabolism in psoriasis patients. Impaired lipid metabolism together with high serum levels of triglycerides have been found in association with OLP. However, the correlation between serum levels of IL-6 and dyslipidemia has not yet been studied in this disorder. The present study aimed to demonstrate the association between OLP, systemic inflammation through increased release of inflammation mediators such as IL-6 and alteration of lipid metabolism, in order to support the concept of OLP as a marker of systemic inflammation and a potential risk factor of cardiovascular morbidities. For this purpose, we designed a case-control study using a cohort of 18 patients with different clinical forms of OLP compared with 18 control group patients with other oral conditions, to identify a potential correlation between serum levels of IL-6 and serum lipid levels. High plasma serum levels of IL-6 were found to be correlated with cholesterol, high density lipoprotein cholesterol and triglyceride serum levels in the patients with OLP. There was a significant association between erosive and atrophic clinical forms of OLP and the pathological serum values of IL-6 and triglycerides, respectively, making these two parameters good predictive factors of the clinical form of OLP. Further studies of other biomarkers of systemic inflammation using larger
\end{abstract}

Correspondence to: Dr Madalina Mocanu, Department of Oral Dermatology, 'Grigore T. Popa' University of Medicine and Pharmacy, 16 University Street, 700115 Iasi, Romania

E-mail: drmadalinamocanu@yahoo.com

Key words: interleukin 6, systemic inflammation, dyslipidemia, total cholesterol, triglycerides, metabolic syndrome, cardiovascular risk, oral lichen planus cohorts of OLP patients are necessary in order to consider LP as a marker of systemic inflammation and to support the screening of these patients for lipid metabolism changes and treatment with specific antagonists in order to prevent cardiovascular events.

\section{Introduction}

Oral lichen planus (OLP) is a chronic inflammatory disorder affecting $1-3 \%$ of the population, with a higher prevalence in women (women to men ratio 1.4:1) (1). Oral lesions of lichen planus may accompany cutaneous lesions or they may be the only sign of the disease. They are considered to be the result of a T-cell-mediated autoimmune response to antigens that may be unmasked by contact allergens such as dental restorative materials, drugs, mechanical trauma or viral infections, leading to activation of auto-cytotoxic $\mathrm{CD} 8^{+} \mathrm{T}$ cells that trigger apoptosis of the basal cells of the oral epithelium (2).

Clinical manifestations of OLP include white striations (Wickham striae), white papules, white plaques, erythema, mucosal atrophy, erosions, or pigmented patches, symmetrically distributed on the oral mucosal membranes. The diagnosis of lichen planus is usually based on clinical aspects correlated with histopathological examination of the lesions. Currently, classical invasive diagnostic methods have been replaced by modern non-invasive techniques (dermoscopy, reflectance confocal microscopy, optical coherence tomography, ultrasound and diffuse reflection spectrophotometry) for the diagnosis and therapeutic monitoring of lichen planus $(3,4)$. These modern methods are useful for appreciating the risk of malignant transformation and an earlier diagnosis of oral squamous carcinoma $(5,6)$.

A chronic relapsing clinical course of OLP has a severe impact on the quality of life of patients, mainly in cases of atrophic and erosive types. The risk of malignant transformation is still debated, with a rate of $0.04-1.7 \%$ reported in the literature, especially in erosive forms and in female patients, or in association with HPV infection $(7,8)$. High levels of IL-6 are also associated with an increase in vascular endothelial growth factor (VEGF) production. VEGF is one of the most important angiogenesis stimulators and it 
has long been demonstrated to facilitate tumor development and metastasis, explaining the correlation between IL-6 and oral squamous cell carcinoma (9).

Current therapeutic options are only partially effective, leading to prolonged local chronic inflammation over the course of several years in these patients $(1,10)$.

Previous reports have focused on the association between LP and alterations in lipid metabolism (11-14), concluding that it may also be associated with a high risk of cardiovascular morbidities (15). Systemic inflammation leads to lipid metabolism disturbances resulting in a redistribution of different nutrients to cells involved in host defense in order to ensure detoxification and tissue repair (16). Prolonged inflammatory status causes prolonged dyslipidemia resulting in atherosclerotic plaque formation and an increase in cardiovascular risk $(17,18)$.

IL-6 is a pleiotropic cytokine with a critical defense role in infections and posttraumatic injuries, promoting the production of IL-1 receptor antagonist, upregulating the synthesis of acute phase proteins in hepatocytes (e.g., reactive $\mathrm{C}$ protein), the terminal differentiation of $\mathrm{B}$ cells into immunoglobulin producing cells and specific differentiation of $\mathrm{T} \mathrm{CD}^{+}$naïve cells into effector $\mathrm{T}$ cell subsets (including antigen-specific Th17 cells) and inhibiting regulatory T cells (19-23). The persistence of proinflammatory IL-6 activity leads to the conversion of acute defense inflammation into chronic damaging inflammatory process (19). This observational case-control study was designed to emphasize the correlation between IL-6, a biomarker of systemic inflammation, and lipid metabolism disturbances in patients with OLP, in order to ascertain whether the disease, even localized oral lesions, may be considered a marker of systemic inflammation and to support the screening of these patients for these disturbances and treating them with IL-6 antagonist aimed to control the cardiovascular risk.

\section{Patients and methods}

We performed an observational case-control study on a cohort of 36 patients diagnosed with several oral mucosal disorders. The patients were divided into two groups: 18 patients with OLP lesions diagnosed clinically and histologically in accordance to the WHO criteria (24) (OLP group) and a control group of 18 patients with other oral manifestations (candidiasis, geographic tongue, canker sore, oral dysesthesia, mucocele and erythema multiforme). Patients over the age of 18 years, without previous treatment with corticosteroids, retinoids or immunosuppressants for 6 months, were included. The study was conducted at the Dermatology Clinic of the University Hospital of the Railways System, Iasi, Romania from January 2015 to December 2019, and patients were followed up for a period of 6 months. Ethical approval from The Ethics Committee of the Railways University Hospital Iasi (Iasi, Romania) and an informed written consent from all 36 enrolled patients were obtained.

Venous blood samples were collected from all patients for analyzing serum levels of IL-6, triglycerides (TG), total cholesterol and high density lipoprotein cholesterol (HDL-C). For this purpose, blood samples were obtained between 8:00 and 9:00 a.m., a jeun, with no alcohol intake during the previous 24 hours. The lipid profile (serum triglycerides,

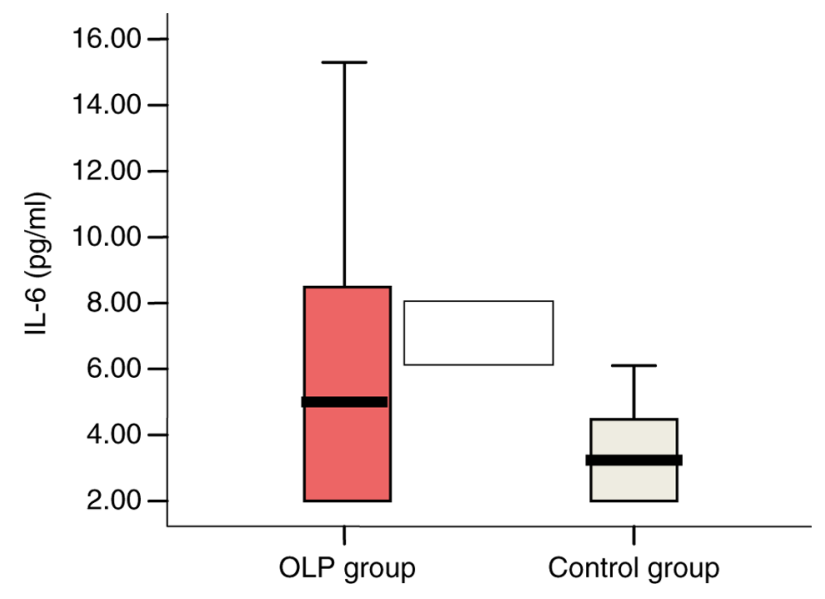

Figure 1. Mean values of IL-6 serum levels in the OLP and control groups. OLP, oral lichen planus; IL-6, interleukin 6.

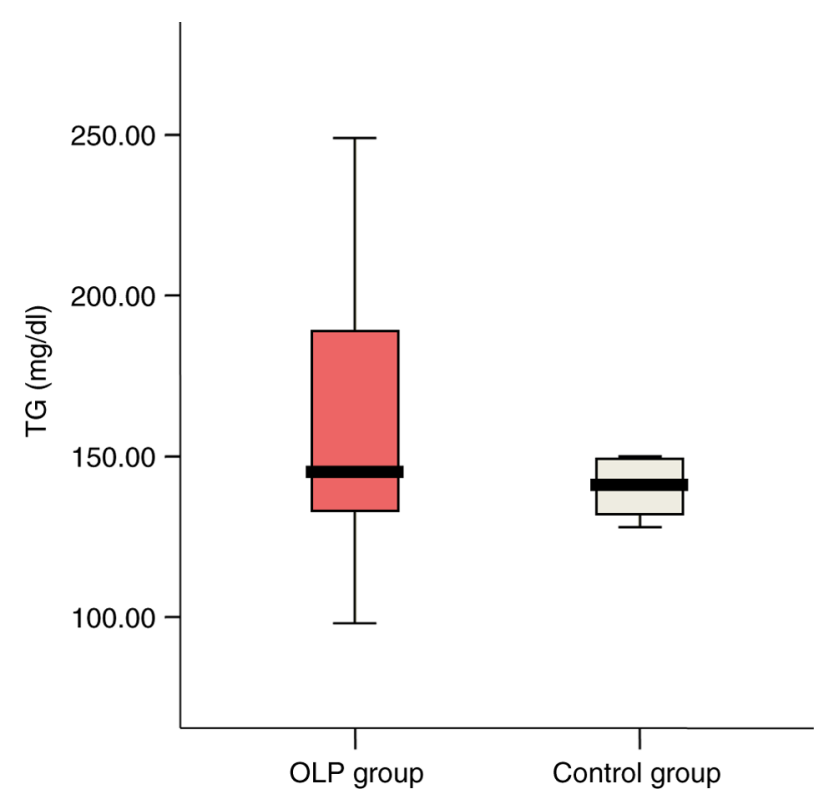

Figure 2. Mean values of TG serum levels in the OLP and control groups. OLP, oral lichen planus; TG, triglycerides.

total cholesterol, HDL-cholesterol) and blood glucose were analyzed using DIASYS (German Diagnostic System $\mathrm{GmbH}$ ) commercial kits on an automated CS-800 machine. Serum IL-6 levels were assessed on blood samples drawn without anticoagulant, centrifuged and frozen at $-80^{\circ} \mathrm{C}$ on an automated IMMULITE 2000 (Siemens) machine using a chemiluminescence technique.

Statistical analysis. Statistical analysis was performed utilizing SPSS version 18.0 software (SPSS, Inc.). ANOVA test was used to demonstrate the relation between intergroup and intragroup variables at 95\% signification threshold and a linear regression analysis was also performed.

\section{Results}

The 36 patients were aged 21-78 years (median 55.21 years) and 24 of them $(66.0 \%)$ were females. In the OLP group, the 

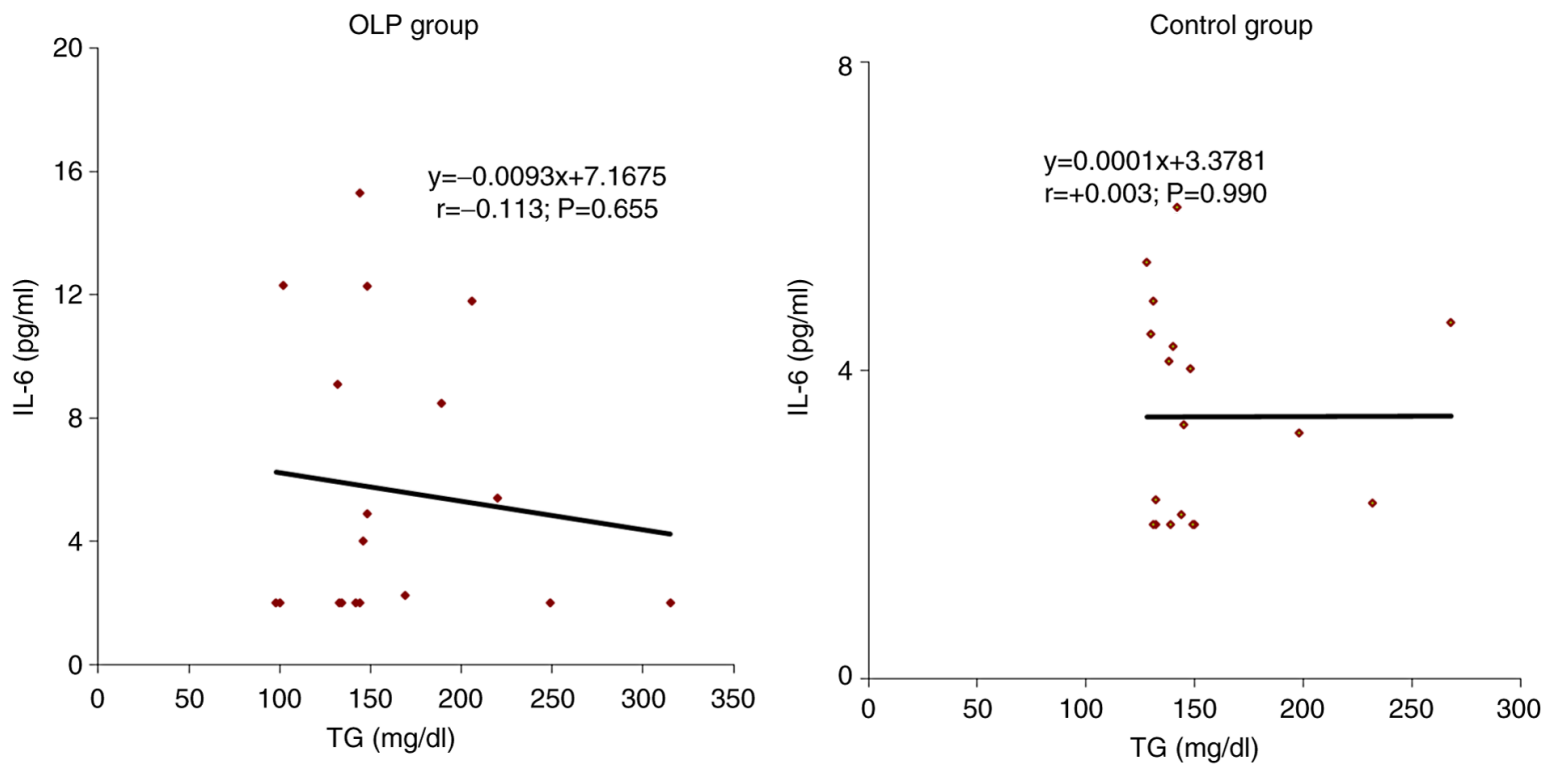

Figure 3. Correlation between serum TG and IL-6 in the OLP (left histogram) and control (right histogram) groups. OLP, oral lichen planus; IL-6, interleukin 6; TG, triglycerides.

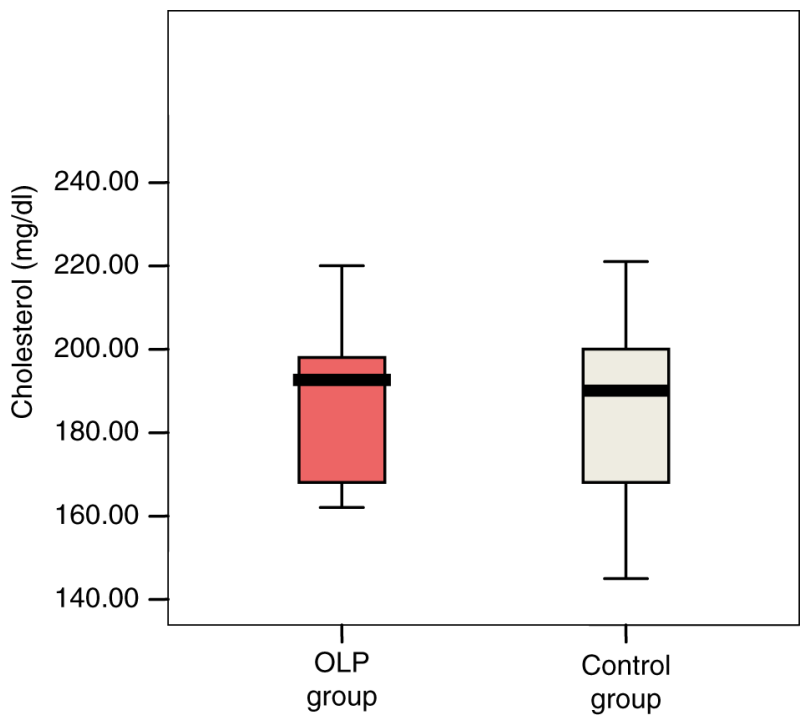

Figure 4. Mean values of serum total cholesterol levels in the OLP and control groups. OLP, oral lichen planus.

sex ratio F:M was 5:1, with 15 cases $(83.3 \%)$ of female patients. The most frequent clinical types of OLP were the atrophic-erosive and erosive forms, diagnosed in 10 cases (55.5\%). One case was in accordance to Grinspan syndrome criteria (OLP, arterial hypertension and type 2 diabetes mellitus) and one case fulfilled the Hewitt-Pelisse syndrome criteria (coexistent lichen planus erosive lesions of gums and genitalia in a 43-year-old woman). The reticular form was present in 5 cases $(27.7 \%)$ and OLP in plaques in 3 cases $(16.6 \%)$. Erosive and atrophic-erosive types of OLP have the most long lasting course, ranging between 8 and 30 months.

High IL-6 serum levels ranging between $8.29 \mathrm{pg} / \mathrm{ml}$ $(>5.9 \mathrm{pg} / \mathrm{ml})$ and $15.30 \mathrm{pg} / \mathrm{ml}$ were found in 6 OLP patients $(33.3 \%)$ vs. 1 patient $(5.5 \%)$ with a value of $6.1 \mathrm{pg} / \mathrm{ml}$ in the control group. Mean values of IL-6 serum levels were significantly higherin the OLP patient group: $5.66 \mathrm{vs.} .3 .40 \mathrm{pg} / \mathrm{ml}$ in the control group $(\mathrm{P}=0.05)$ (Fig. 1).

High TG serum levels $(>150 \mathrm{mg} / \mathrm{dl})$ were detected in $33.3 \%$ (6 patients) of OLP group vs. 16.7\% (3 cases) in the control group. Mean value was slightly higher in the OLP group (162.171 vs. $154.28 \mathrm{mg} / \mathrm{dl} ; \mathrm{P}=0.625$ ) (Fig. 2).

The correlations of IL- 6 with individual values of serum TG was indirect, of low intensity in patients with OLP $(\mathrm{r}=-0.113 ; \mathrm{P}=0.655)$ and these parameters were independent in those from the control group ( $\mathrm{r}=0.003$; $\mathrm{P}=0.990)$ (Fig. 3).

Cholesterol serum levels ranged between 145-298 mg/dl, extreme values being recorded in the OLP patient group. Mean values were slightly higher in patients with OLP compared with controls (194.78 vs. $194.72 \mathrm{mg} / \mathrm{dl}$; $\mathrm{P}=0.921)$ (Fig. 4).

In the OLP group, the correlation of IL-6 with individual values of serum total cholesterol was direct, of moderate intensity ( $\mathrm{r}=0.685 ; \mathrm{P}=0.014)$, a result that can be extrapolated to the general population. In the control group, the correlation of IL-6 with total cholesterol serum values was also direct but of low intensity ( $r=0.120 ; \mathrm{P}=0.636$ ) (Fig. 5).

HDL-C serum values ranged between 35 and $54 \mathrm{mg} / \mathrm{dl}$ in the OLP group. Pathological individual values were recorded in $27.8 \%$ of these patients vs. $72.2 \%$ of controls. Mean values were slightly higher in OLP cases compared with controls (43.11 vs. $41.28 \mathrm{mg} / \mathrm{dl}$; $\mathrm{P}=0.342$ ) (Fig. 6).

The correlation of IL- 6 with individual values of HDL-C in OLP patients was direct, of moderate intensity $(r=0.565$; $\mathrm{P}=0.014)$. In $56.5 \%$ of cases, lower levels of HDL-C and high levels of IL- 6 were recorded. In the control group, the correlation of IL-6 with HDL-C serum levels was also direct but of low intensity ( $r=0.109 ; \mathrm{P}=0.666$ ) (Fig. 7).

The highest IL-6 mean serum value was recorded in patients with erosive lesions of OLP $(9.25 \mathrm{pg} / \mathrm{ml})$ and atrophic-erosive clinical form $(8.47 \mathrm{pg} / \mathrm{ml})$ (Fig. 8).

The mean value of serum TG was significantly different depending on the clinical form of OLP; mean value was higher in OLP with erosive and atrophic lesions, ranging 

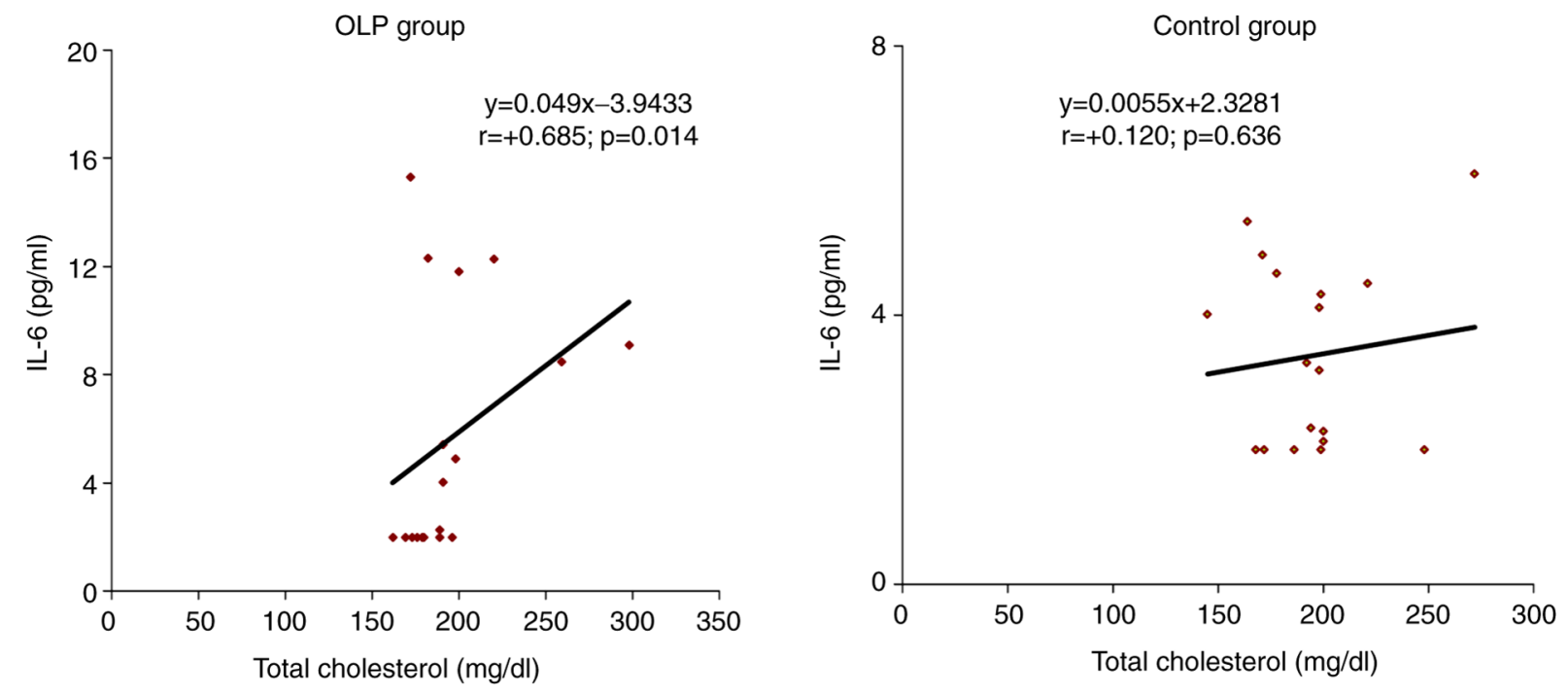

Figure 5. Correlation between total cholesterol serum and IL6 in the OLP (left histogram) and control (right histogram) groups. OLP, oral lichen planus; IL-6, interleukin 6.

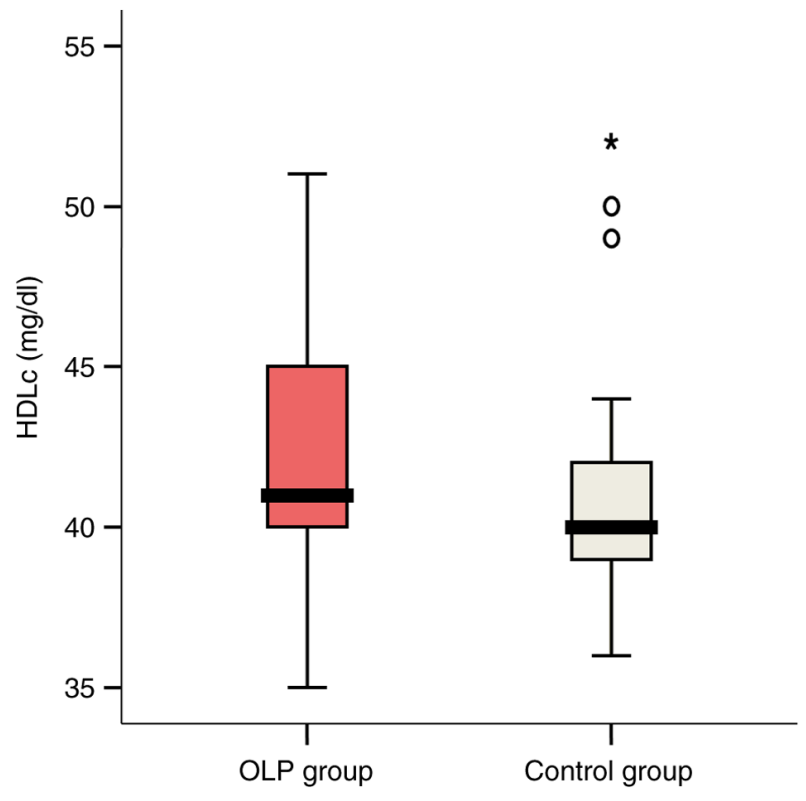

Figure 6. Correlation between HDL-C and IL6 in the two study groups.

from $189 \mathrm{mg} / \mathrm{ml}$ in atrophic-erosive form to $100 \mathrm{mg} / \mathrm{ml}$ in vulvo-vagino-gingival syndrome ( $\mathrm{P}=0.05)$ (Fig. 9).

The highest mean value of serum total cholesterol was recorded in patients with atrophic-erosive clinical forms $(259 \mathrm{mg} / \mathrm{dl})$. However, mean serum cholesterol values were not dependent on the clinical aspect of OLP (Fig. 10).

No significant differences were observed between clinical forms of OLP with respect to mean serum HDL-C values (Fig. 11).

There was an association between erosive clinical forms of OLP and the pathological serum values of IL- 6 and TG respectively. Thus, these two parameters would be valuable predictive factors of the clinical form of OLP. Serum levels of all the studied parameters in relation to the clinical forms of OLP are presented in Table I.

\section{Discussion}

OLP is the most frequent mucosal involvement of a chronic inflammatory muco-cutaneous disease. Recent studies emphasize the association between LP, dyslipidemia, systemic inflammation and cardiovascular risk (11,13,14,25-28). Alterations in serum plasma lipid profile occur normally during inflammatory processes in order to annihilate the toxicity of causative agents and promote tissue repair $(16,17)$. Although LP etiology and pathogenesis are still not completely understood, current scientific data support the hypothesis of $\mathrm{T}$ cell-mediated disease in which proinflammatory cytokines [e.g., tumor necrosis factor (TNF) $\alpha$, interleukin (IL)-2, IL-4, IL-6, IL-10] secreted by various cells including activated keratinocytes and cytotoxic $\mathrm{CD} 8^{+} \mathrm{T}$ cells, participate in perpetuating and persistence of inflammation (11). Recent research regarding cardiovascular risk in psoriasis suggests that chronic inflammation may be considered a component of the metabolic syndrome in which activation of type $1 \mathrm{~T}$ helper cells is present. The upregulation of type $1 \mathrm{~T}$ helper cells was observed in metabolic syndrome in correlation with several cytokines such as IL-6 and TNF $\alpha$ (29-31). IL-6 is a pleiotropic cytokine with a critical defense role in acute inflammatory response during infections and posttraumatic tissue injuries, promoting the synthesis of acute phase proteins including reactive $\mathrm{C}$ protein, amyloid $\mathrm{A}$ and fibrinogen. This acute phase response is associated with increased blood viscosity and increased number of activated platelets. High plasma levels of fibrinogen contributes to the decrease in serum levels of HDL-cholesterol. Deposition of fibrinogen in the vascular endothelium is stimulated by IL- 6 activation and represents a risk factor for cardiovascular morbidity (32). Recent research suggests IL-6 as an important mediator of atherosclerosis, as a high serum level of IL-6 is associated with the onset of acute coronary disease and other ischemic conditions (33).

IL-6 is also involved in the upregulation of terminal differentiation of B cells into immunoglobulin-producing plasma cells and differentiation of naïve $\mathrm{TCD}^{+}$cells 

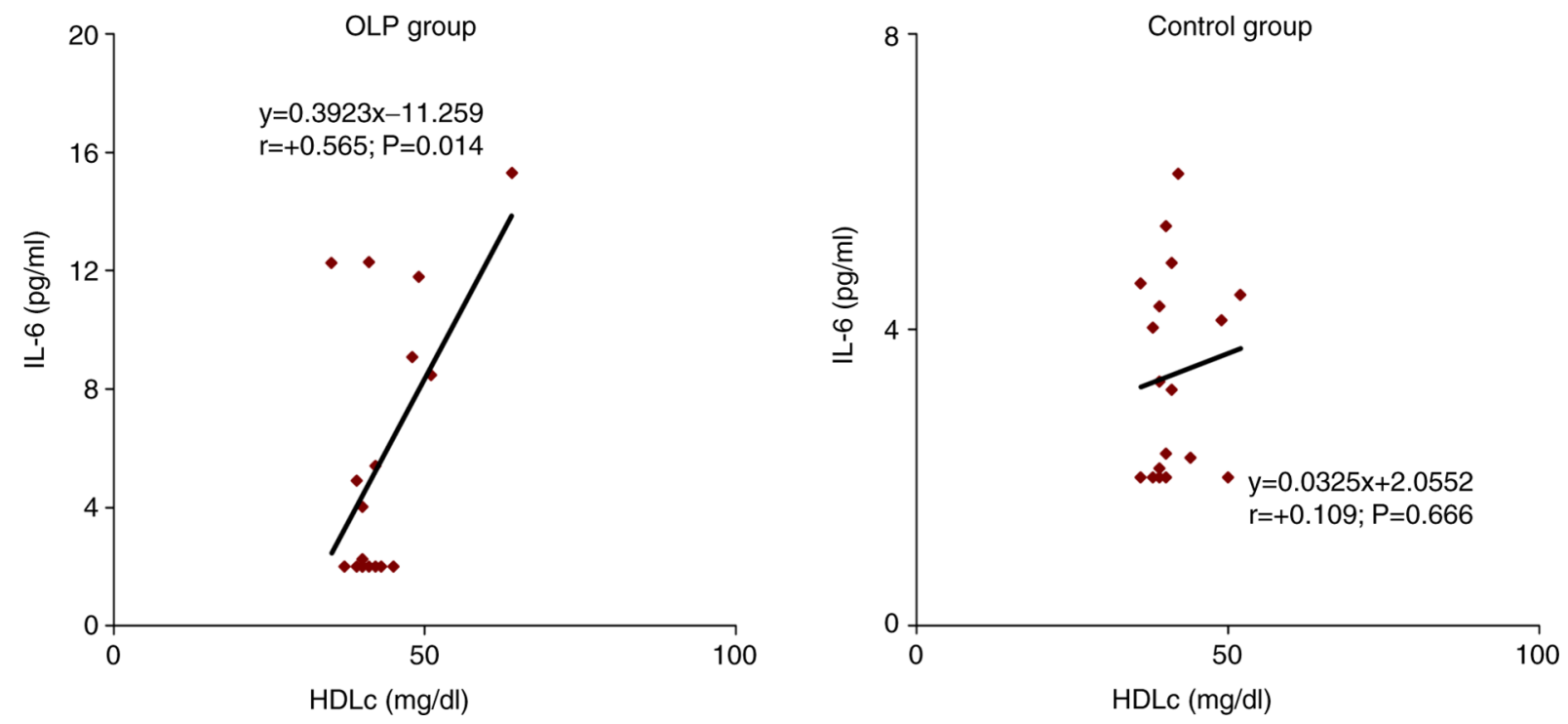

Figure 7. Intensity (P-value, r) of the correlation between HDL-C and IL-6 in the OLP (left histogram) and control (right histogram) groups. OLP, oral lichen planus; IL-6, interleukin 6 .

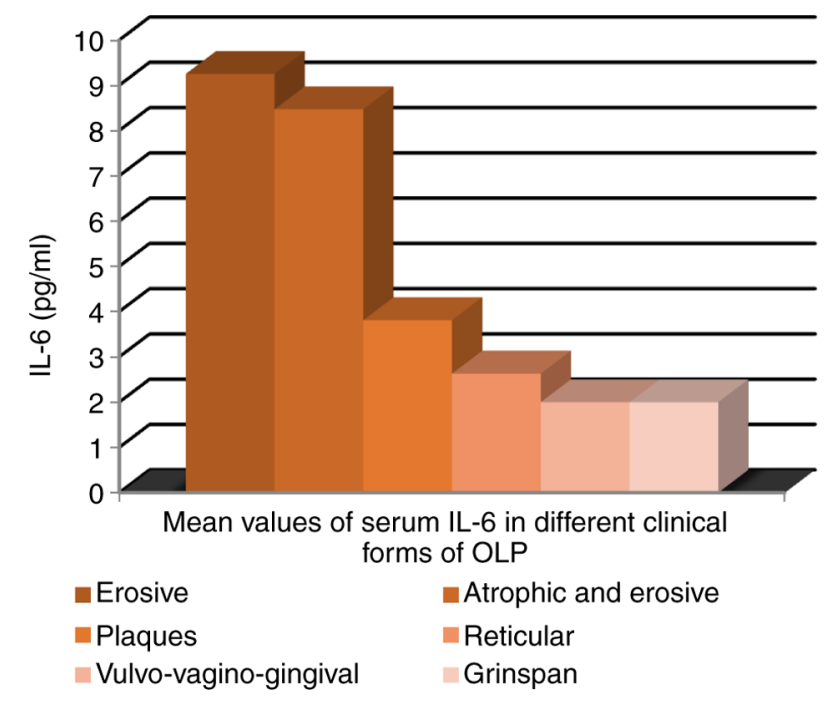

Figure 8. Mean values of serum IL-6 in different clinical forms of OLP. OLP, oral lichen planus; IL-6, interleukin 6.

into antigen-specific Th17 effector cells (17). It also downregulates regulatory $\mathrm{T}$ cells leading to immune tolerance suppression and subsequent development of autoimmune and inflammatory reaction (19). Disturbances in IL-6 secretion resulting in high serum plasma levels and persistence of its proinflammatory activity leads to the conversion of acute inflammatory response to chronic inflammatory process (33). High serum levels of IL-6 have been recorded in rheumatoid arthritis, systemic juvenile idiopathic arthritis, systemic lupus erythematosus, psoriasis, Crohn disease and ankylosing spondylitis $(22,34)$. Tocilizumab, a monoclonal humanized IgG1 class antibody which inhibits IL-6 binding to its soluble and transmembrane receptors was approved in over 100 countries for rheumatoid arthritis treatment (35). The involvement of IL-6 in general metabolic control was also demonstrated. Studies suggest that in obese

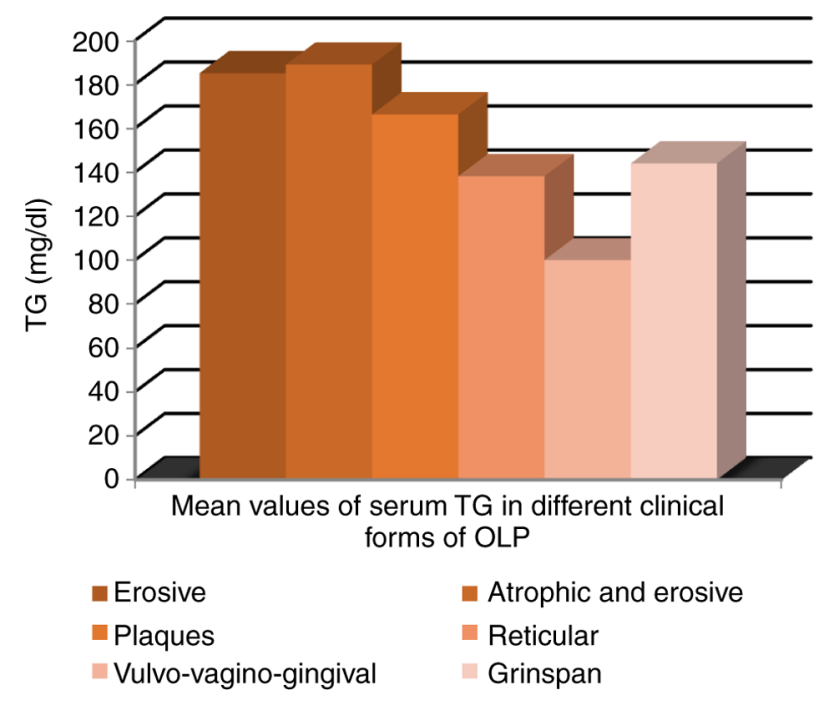

Figure 9. Mean values of serum TG in different clinical forms of OLP. OLP, oral lichen planus; TG, triglycerides.

persons, IL-6 secretion in adipocytes correlates with the size of these cells (18). Experimental research showed that IL6-deficient mice developed glucose intolerance, systemic insulin resistance, hepatic inflammation and mature-onset obesity $(36,37,38)$. Given the important pathogenic role of IL-6 in a multitude of inflammatory, autoimmune and even proliferative conditions (e.g., multiple myeloma) we found it useful to study its involvement in lipid metabolic disturbances in patients with OLP.

The current observational study demonstrated that in patients with OLP, lipid serum profile changes are present and there is a correlation between dyslipidemia and IL-6 as an important marker of systemic inflammation. Thus, high IL-6 serum levels were recorded in $33.3 \%$ cases of OLP vs. $5.6 \%$ in the control group and mean IL- 6 values were significantly higher in patients with OLP (5.66 vs. $3.40 \mathrm{pg} / \mathrm{ml}$; $\mathrm{P}=0.05)$. Our 
Table I. Serum levels of IL-6 (pg/ml), triglycerides (mg/dl), total cholesterol (mg/dl) and HDL cholesterol (mg/dl) in relation with the clinical form of OLP.

\begin{tabular}{|c|c|c|c|c|c|c|c|c|c|c|c|c|c|}
\hline \multirow[b]{2}{*}{ Clinical form of OLP } & \multirow{2}{*}{$\begin{array}{l}\text { No. of } \\
\text { patients }\end{array}$} & \multicolumn{3}{|c|}{$\begin{array}{l}\text { Serum IL-6 levels } \\
(\mathrm{pg} / \mathrm{ml}) \mathrm{P}=0.007\end{array}$} & \multicolumn{3}{|c|}{$\begin{array}{l}\text { Serum triglycerides } \\
\qquad(\mathrm{mg} / \mathrm{dl}) \mathrm{P}=0.05\end{array}$} & \multicolumn{3}{|c|}{$\begin{array}{l}\text { Serum total cholesterol } \\
\quad(\mathrm{mg} / \mathrm{dl}) \mathrm{P}=0.259\end{array}$} & \multicolumn{3}{|c|}{$\begin{array}{l}\text { Serum HDL-C } \\
(\mathrm{mg} / \mathrm{dl}) \mathrm{P}=0.530\end{array}$} \\
\hline & & Mean & Min. & Max. & Mean & Min. & Max. & Mean & Min. & Max. & Mean & Min. & Max. \\
\hline & 7 & & & 15.30 & & & & & & & 45.57 & & 64.00 \\
\hline Atrophic and erosive & 1 & 8.47 & 8.47 & 8.47 & 189.00 & 189.00 & 189.00 & 259.00 & 259.00 & 259.00 & 51.00 & 51.00 & 51.00 \\
\hline Plaques & 3 & 3.81 & $<2.00$ & 5.40 & 166.33 & 133.00 & 220.00 & 181.33 & 162.00 & 191.00 & 42.33 & 40.00 & 45.00 \\
\hline Retic & 5 & 2.63 & $<2.00$ & 4.90 & 138.20 & 98.00 & 169.00 & 183.00 & 169.00 & 198.00 & 39.80 & 39.00 & 41.00 \\
\hline Vulvo-vagino- & 1 & 2.00 & 2.00 & 2.00 & 100.00 & 100.00 & 100.00 & 176.00 & 176.00 & 176.00 & 43.00 & 43.00 & 43.00 \\
\hline Grinspan's syndrome & 1 & 2.00 & 2.00 & 2.00 & 144.00 & 144.00 & 144.00 & 173.00 & 173.00 & 173.00 & 37.00 & 37.00 & 37.00 \\
\hline
\end{tabular}

IL-6, interleukin 6; OLP, oral lichen planus.

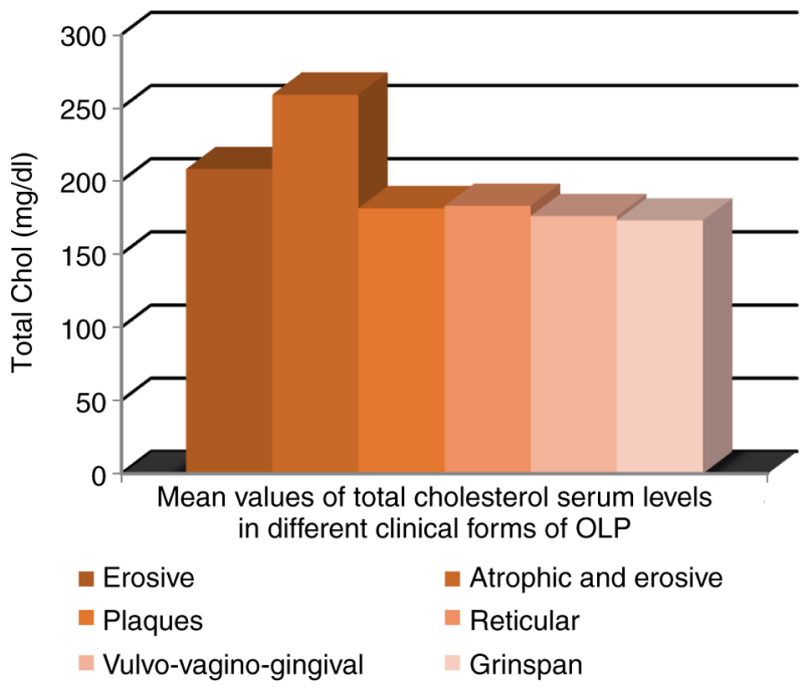

Figure 10. Mean values of total cholesterol serum levels in different clinical forms of OLP. OLP, oral lichen planus.

findings support other studies that showed similar results, with IL-6 levels of serum and saliva significantly higher in patients with OLP (13).

High serum TG levels were found in a higher proportion OLP cases vs. controls, with TG mean values slightly higher in OLP patients, but without statistical significance (162.17 vs. $154.28 \mathrm{mg} / \mathrm{dl} ; \mathrm{P}=0.625)$. Total cholesterol levels were higher in an equal proportion in the two groups (16.7\%) but with slightly higher mean values in the OLP group. Pathologic HDL-C serum levels were found in $27.8 \%$ of OLP cases. Our findings regarding dyslipidemia in OLP is in accordance with recent studies suggesting that patients with OLP display more impaired lipid metabolism alteration than patients with classic cutaneous lichen planus (39).

We found that IL-6 serum levels in patients with OLP correlated with all the studied parameters of lipid metabolism. There was a significant direct and moderate correlation between IL- 6 and individual mean cholesterol values $(\mathrm{r}=0.685 ; \mathrm{P}=0.014)$ in the OLP group. The correlation

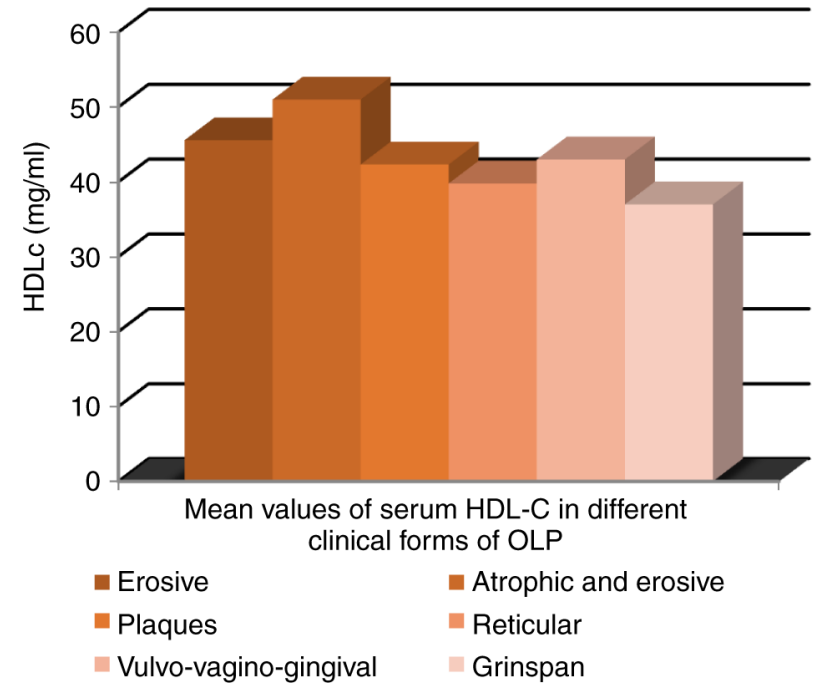

Figure 11. Mean values of serum HDL-C in different clinical forms of OLP. OLP, oral lichen planus.

of IL-6 with individual HDL-C values was moderate and direct $(r=0.565 ; \mathrm{P}=0.014)$, result that can be extrapolated to the general population. The correlation between serum levels of IL-6 and TG in OLP cases was indirect ( $\mathrm{r}=-0.113$; $\mathrm{P}=0.655)$ vs. the control group, where these parameters were independent.

We must emphasize that the highest IL- 6 mean serum values were recorded in erosive and atrophic-erosive OLP lesions, which can be explained by the long-lasting course of these clinical forms (8-30 months) meaning a prolonged inflammatory status. TG serum levels were also different in regards to the clinical forms of OLP, the highest mean value $(189 \mathrm{mg} / \mathrm{ml})$ being recorded in patients with atrophic-erosive lesions. Thus, we may consider IL-6 and triglycerides good predictive factors of the OLP clinical form.

The present study has several limitations. The study included a small number of patients and the period of survey was short. We did not take into account other risk factors for dyslipidemia (such as tobacco and alcohol consumption, 
diabetes mellitus, sedentary lifestyle) and the presence of cardiovascular and hepatic comorbidities in our patients.

In conclusion, the current observational case-control study was designed and carried out to demonstrate the correlation between OLP and systemic inflammation via the enhanced production of IL-6, a biomarker of systemic inflammation and disturbance of serum lipid profile. Our results suggest that this chronic inflammatory condition may be considered a potential marker of systemic inflammation and a cardiovascular risk factor. The findings should be completed and interpreted in conjunction with results of larger future studies aimed at other biomarkers of systemic inflammation. However, OLP patients should be monitored for anomalies of lipid metabolism and cardiovascular comorbidities.

\section{Acknowledgements}

Not applicable.

\section{Funding}

The study was partly funded by a research grant from the Romanian Society of Dermatology.

\section{Availability of data and materials}

The data that support the findings of this study are available from the archives of the Railways University Hospital Iasi, (Iasi, Romania), but restrictions apply to the availability of these data which are not publicly available. Data are, however, available from the authors upon reasonable request and with permission from the Railways University Hospital Iasi.

\section{Authors' contributions}

MPT, TT and MMC conceived and supervised the study. MPT, VVC and DO were responsible for the collection and analysis of the experimental data. MM and ST performed the statistical analysis, created the figures and drafted the manuscript. All authors contributed equally to acquisition, analysis and systematization of data, manuscript writing and critical revision of the manuscript for important intellectual content. All the authors read and approved the final version of the manuscript.

\section{Ethics approval and consent to participate}

The Ethics Committee of the Railways University Hospital Iasi (Iasi, Romania) approved the current study. Informed written consent from all 36 enrolled patients was obtained.

\section{Patient consent for publication}

Not applicable.

\section{Competing interests}

The authors declare that they have no competing interests.

\section{References}

1. De Rossi SS and Ciarrocca K: Oral lichen planus and lichenoid mucositis. Dent Clin North Am 58: 299-313, 2014.

2. Popovska M, Radojkova-Nikolovska V, Minovska A, Agop Forna D, Muratovska I and Forna NC: Etiopathogenic biochemical mechanism involved in oral lichen planus. Rev Chim 66: 1786-1790, 2015.

3. Ianosi SL, Forsea AM, Lupu M, Ilie MA, Zurac S, Boda D, Ianosi G, Neagoe D, Tutunaru C, Popa CM and Caruntu C: Role of modern imaging techniques for the in vivo diagnosis of lichen planus. Exp Ther Med 17: 1052-1060, 2019.

4. Lupu M, Caruntu A, Caruntu C, Boda D, Moraru L, Voiculescu V and Bastian A: Non-invasive imaging of actinic cheilitis and squamous cell carcinoma of the lip. Mol Clin Oncol 8: 640-646, 2018.

5. Lupu M, Căruntu A, Moraru L, Voiculescu VM, Boda D, Tanase $C$ and Căruntu C: Non-invasive imaging techniques for early diagnosis of radiation-induced squamous cell carcinoma of the lip. Rom J Morphol Embryol 59: 949-953, 2018.

6. Calenic B, Greabu M, Caruntu C, Nicolescu MI, Moraru L, Surdu-Bob CC, Badulescu M, Anghel A, Logofatu C and Boda D: Oral keratinocyte stem cells behavior on diamond like carbon films. Rom Biotechnol Lett 21: 11914-11922, 2016.

7. Boda D, Docea AO, Calina D, Ilie MA, Caruntu C, Zurac S, Neagu M, Constantin C, Branisteanu DE, Voiculescu V, et al: Human papilloma virus: Apprehending the link with carcinogenesis and unveiling new research avenues. Int J Oncol 52: 637-655, 2018.

8. Boda D,Neagu M, Constantin C, Voinescu RN, Caruntu C,Zurac S, Spandidos DA, Drakoulis N, Tsoukalas D and Tsatsakis AM: HPV strain distribution in patients with genital warts in a female population sample. Oncol Lett 12: 1779-1782, 2016.

9. Solomon I, Voiculescu VM, Caruntu C, Lupu M, Popa A, Ilie MA, Albulescu R, Caruntu A, Tanase C, Constantin C, et al: Neuroendocrine factors and head and neck squamous cell carcinoma: An affair to remember. Dis Markers 2018: 9787831, 2018.

10. Giuliani M, Troiano G, Cordaro M, Corsalini M, Gioco G, Lo Muzio L, Pignatelli P and Lajolo C: Rate of malignant transformation of oral lichen planus: A systematic review. Oral Dis 25: 693-709, 2019.

11. Aniyan KY, Guledgud MV and Patil K: Alterations of serum lipid profile patterns in oral lichen planus patients: A case-control study. Contemp Clin Dent 9 (Suppl 1): S112-S121, 2018.

12. Sezer E, Ozugurlu F, Ozyurt H, Sahin S and Etikan I: Lipid peroxidation and antioxidant status in lichen planus. Clin Exp Dermatol 32: 430-434, 2007.

13. Lai YC, Yew YW and Schwartz RA: Lichen planus and dyslipidemia: A systematic review and meta-analysis of observational studies. Int J Dermatol 55: e295-e304, 2016.

14. Ozbagcivan O, Akarsu S, Semiz F and Fetil E: Comparison of serum lipid parameters between patients with classic cutaneous lichen planus and oral lichen planus. Clin Oral Investig 24: 719-725, 2020

15. Arias-Santiago S, Eisman AB, Fernandez JA, Girón-Prieto MS, Gutiérrez-Salmerón MT, García Mellado V and Naranjo-Sintes R: Cardiovascular risk factors in patients with lichen planus. Am J Med 124: 543-548, 2011.

16. Esteve E, Ricart W and Fernández-Real JM: Dyslipidemia and inflammation: An evolutionary conserved mechanism. Clin Nutr 24: 16-31, 2005.

17. Krishnamoorthy B, Suma GN, Mamatha NS, Sowbhagya MB and Komali Garlapati: Lipid profile and metabolic syndrome status in patients with oral lichen planus, oral lichenoid reactions and healthy individuals attending a dental college in Northern India - a descriptive study. J Clin Diagn Res 8: ZC92-ZC95, 2014.

18. Hotamisigil GS: Inflammation and metabolic disorders. Nature 444: 860-867, 2006.

19. Scheller J, Chalaris A, Schmidt-Aras D and Rose-John S: The pro- and anti-inflammatory properties of the cytokine interleukin-6. Biochim Biophys Act 1813: 878-888, 2011.

20. Xing Z, Gauldie J, Cox G, Baumann H, Jordana M, Lei XF and Achong MK: IL6 is an antiinflammatory cytokine required for controlling local or systemic acute inflammatory responses. J Clin Invest 101: 311-320, 1998.

21. Paquet $P$ and Piérard GE: Interleukin-6 and the skin. Int Arch Allergy Immunol 109: 308-317, 1996.

22. Lipsky PE: Interleukin-6 and rheumatic diseases. Arthritis Res Ther 8 (Suppl 2): S4, 2006. 
23. Khishimoto T: Interleukin-6: Discovery of a pleiotropic cytokine. Arthritis Res Ther 8 (Suppl 2): S2, 2006.

24. Patil S, Roopa SR, Sanketh DS, Sarode SC and Sarode GS: A universal diagnostic criteria for oral lichen planus: An exigency!. Int J Contemp Dental Medical Rev: 1-4, 2014.

25. Baykal L, Arıca DA, Yaylı S, Örem A, Bahadır S, Altun E and Yaman H: Prevalence of metabolic syndrome in patients with lichen planus. A case-control study. Am J Clin Dermatol 16 439-445, 2005

26. Romero MA, Seoane J, Varela-Centelles P, Diz-Dios P and Garcia-Pola MJ: Prevalence of diabetes mellitus amongst oral lichen planus patients. Clinical and pathological characteristics. Med Oral 7: 121-129, 2002 (In English, Spanish).

27. Eisen D: The clinical features, malignant potential and systemic associations of oral lichen planus: A study of 723 patients. J Am Acad Dermatol 46: 207-214, 2002.

28. Lopez-Jornet P, Alonso CF and Rodríguez-Martines MA: Alterations in serum lipid profile patterns in oral lichen planus. A cross-sectional study. Am J Clin Dermatol 13: 399-404, 2012.

29. Neimann AL, Shin DB, Wang X, Margolis DJ, Troxel AB and Gelfand JM: Prevalence of cardiovascular risk factors in patients with psoriasis. J Am Acad Dermatol 55: 829-835, 2006.

30. Sommer DM, Jenish S, Suchan M, Christophers E and Weichenthal M: Increased prevalence of the metabolic syndrome in patients with moderate to severe psoriasis. Arch Dermatol Res 298: 321-328, 2006

31. Grechin C, Solovăstru LG, Vâță D, Pătrașcu AI, Grăjdeanu AI and Porumb-Andrese E: Inflammatory marker alteration in response to systemic therapies in psoriasis. Exp Ther Med 20: $42-46,2020$
32. Boda D and Dehelean C: Immuno-dermatological processes involved in chronic skin diseases: Highlights of the Second Conference of the Romanian Society for Immuno-Dermatology, Bucharest. Exp Ther Med 18: 873-874, 2018.

33. Narazaki M and Kishimoto T: The two-faced cytokine IL-6 in host defenseand diseases. Int J Mol Sci 19: 3528, 2018

34. Pauli N, Puchałowicz K, Kuligowska A, Krzystolik A, Dziedziejko V, Safranow K, Rać M, Chlubek D and Rać ME: Associations between IL-6 and echo-parameters in patients with early onset coronary artery disease. Diagnostics (Basel) 9: 189, 2019.

35. Gabay C: Interleukin-6 and chronic inflammation. Arthritis Res Ther 8 (Suppl 2): S3, 2006.

36. Tanaka T,Narazaki M, Masuda K and Kishimoto T: Interleukin-6: Pathogenesis and treatment of autoimmune inflammatory diseases. Inflam Regeneratin 33: 54-65, 2013.

37. Tanaka T, Narazaki M and Kishimoto T: Therapeutic targeting of interleukin-6 receptor. Ann Rev Pharmacol Toxicol 52: 199-219, 2012.

38. Wallenius V, Wallenius K, Ahrén B, Rudling M, Carlsten H, Dickson SL, Ohlsson C and Jansson JO: Interleukin-6 deficient mice develop mature-onset obesity. Nat Med 8: 75-79, 2002.

39. Matthews VB, Allen TL, Risis S, Chan MH, Henstridge DC, Watson N, Zaffino LA, Babb JR, Boon J, Meikle PJ, et al: Interleukin-6-deficient mice develop hepatic inflammation and systemic insulin resistance. Diabetologia 53: 2431-2441, 2010.

This work is licensed under a Creative Commons Attribution-NonCommercial-NoDerivatives 4.0 International (CC BY-NC-ND 4.0) License. 